\title{
Trends in Research for human benefit
}

\section{Hiroyuki Aizawa*}

Aizawa Science Museum, Kasukabe, Saitama, Japan

Revolution of natural science has changed humanity and social science since $17^{\text {th }}$ century. Principles of science were established in $18^{\text {th }}$ century under the patronage of royalty, and civilized citizens played a central role in industrial revolution around $19^{\text {th }}$ century.

Since the middle of $20^{\text {th }}$ century, life science has progressed based on the development of molecular and cellular biology. Genetic engineering has made it possible to create new species of bacteria whose genome is designed and synthesized by humans. Developmental biology has enabled us to produce clone animals from frog to sheep using somatic cell nuclear transplantation technology. Human genome project has unveiled the secret of human heredity and body plan. Research on induced pluripotent stem cells discovered sophisticated regulatory system of gene expression during development. In regenerative medicine, physicians treat patients with transplantation of engineered tissues such as bone marrow, blood vessel, skin, bone, tooth, and epithelial cell sheet. Within the $21^{\text {st }}$ century, neuroscientists will discover the molecular mechanism of human mind for treatment of mental disorders. They are now focusing on the mystery of memory, emotion, and consciousness. Electric regulation of biological membranes may play a central role in human mind.

Along with the scientific progress, medicine plays a central role in increase of population, life span, and quality of life of humans with the aid of pharmaceutical, agricultural, and food science technology. For example, antibiotics help millions of people from infectious diseases every year. Moreover, dietary supplement of vitamins greatly improves healthy conditions for people to prevent disease.

On the other hand, we have still various problems to be solved for human health. In some countries, for example, short of food supply causes serious problem for human health conditions. Number of cancer patients keeps on growing all over the world. More than one fifteenth of total population of humans are getting diabetes in the world. And human beings suffer from heart attacks, strokes, and mental disorders such as Alzheimer's disease. From all over the world, furthermore, various types of new diseases are discovered for the first time and reported annually.

While recent advances in medical science give a line of insights to address these problems, we need preclinical and clinical research on these diseases for establishment of effective treatments for those medical conditions. In medicine, research comes from diagnoses and clinical study on patients by physicians. Especially, diagnosis or case report plays a central role in discovery of novel diseases. A line of evidences of some diseases, that is, case series may not only confirm each case report but also give insights to recognize common and essential features of a disease for its identification. Using big data, epidemiology discovers association between disease and its risk factors not only in a medical condition but also in humanity, social, and environmental conditions.

Medical and life scientists have right and obligation to study for human benefit. For maximizing and minimizing merit and risk of research, respectively, it is essential to exchange, share, and discuss on clinical case reports and idea among physicians, life scientists, academic professors, and students. Open access journal is exactly one resolution for this issue. Accordingly, Trends in Research is willing to publish any types of scientific study as original research, case study, technical advances, book review, perspectives, or opinions in clinical, medical, surgical, pharmaceutical, agricultural, food, and life science as an open resource of medical society. Rigid and reliable data are critically essential to accumulation of medical knowledge for public good.

I hope that all the readers of this journal may become informed and get insights of research and development in medical and life science.
Copyright: (C)2018 Aizawa H. This is an open-access article distributed under the terms of the Creative Commons Attribution License, which permits unrestricted use, distribution, and reproduction in any medium, provided the original author and source are credited.
*Correspondence to: Hiroyuki Aizawa, Aizawa Science Museum, 1-10-13 Yutaka-cho, Kasukabe, Saitama 3440066, Japan, Tel: +81-48-754-9880; Fax: +81-48-754-9880, E-mail: aizawa@rr.iij4u.or.jp

Received: September 10, 2018; Accepted: September 18, 2018; Published: September 20, 2018 